\title{
Reading Preferences of ESL Students: Electronic Texts vs. Printed
}

\author{
https://doi.org/10.3991/ijet.v14.i04.9466 \\ Basim Alamri \\ King Abdulaziz University, Jeddah, Saudi Arabia \\ bmalamri@kau.edu.sa
}

\begin{abstract}
The present study investigated the reading preferences of international students regarding their choices between electronic texts (e-texts) and printed texts (p-texts). The study also explored the influence of reading e-texts and p-texts on comprehending their contents, as well as the purpose of students using these electronic devices (e-devices). The data were collected using a questionnaire completed by non-native English speakers (36 males, 24 females) at a southwestern university in the United States. The findings indicated that the students preferred using p-texts over e-texts. Among these students, there was no gender difference in terms of reading preferences. Moreover, the results indicated a statistically significant difference between males and females regarding understanding the content in the printed format. The females understood the content better than the males when they read p-text. The findings also revealed that students preferred using electronic devices for personal uses rather than academic uses. Such personal uses were web browsing, listening to or watching media, and reading and writing emails. The study suggested several pedagogical implications for students and e-book developers and designers.
\end{abstract}

Keywords-Electronic text, printed text, second language reading, electronic devices

\section{Introduction}

Online reading has become widely used among college students. [2] define online reading as a "moment-by-moment processing of text during reading" (p. 70). New devices and integrated tools have played a significant role in improving the choices offered for reading in English. As these devices are available everywhere and can be bought from stores, the continued evolution of electronic texts is now challenging the availability of the printed ones. The differences between electronic texts (e-texts) and printed texts (p-texts) depend on their features and the people who use them. Some people prefer using p-texts for certain reasons, while others have their own opinions when it comes to reading e-texts. A p-text is an actual paper text that people borrow or purchase from traditional libraries and bookstores. On the other hand, an e-text is "an electronic version of a textbook presented in software form" [1]. 
E-books have progressed through several phases and formats. These phases have started by Project Gutenberg in 1971 which established the first online library initially, then moved to Portable Document Format (PDFs), and later in 2011 Google Books website, which scans the physical books to create PDF documents and uploads them to the web. In fact, many e-books are now "born digital" [3] as they are created online, accessible only via the web, and are totally separate entities from their printed counterparts. These new formats can be read by numerous popular devices and tools, such as Kindle, tablets, computers, mobile phones, and navigation devices [4].

Interestingly, students carry their electronic devices (e-devices) (i.e., laptops, tablets, and cellphones) everywhere they go, even at a university. Students perhaps use these devices when doing their assignments and reading course materials, or to increase their reading comprehension or to download all the course materials to their devices in order to use them occasionally. Therefore, the purpose of the study was to find out whether international ESL students preferred using traditional texts (t-texts) or electronic texts (e-texts) for reading their course materials. In addition, the study explored the influence of reading e-text on the students' understanding of the content. Personal and academic uses of electronic devices were also investigated. The study intended to answer the following questions:

- What type of text format (printed or electronic) do students prefer for reading course materials?

- Is there a difference between males and females in terms of reading preferences?

- Is there a difference between males and females in terms of reading comprehension with e-texts and t-texts?

- How do students use electronic devices (i.e., tablets)?

\section{Literature Review}

Several research studies have explored the use of electronic texts and their effects on second language reading. These studies also attempted to find out preferences regarding the use of electronic text or printed text for reading course materials and reasons behind this preference. Surprisingly, the majority of studies revealed that a large number of readers still prefer using p-texts [5], [6], [7], [8]. Other studies investigated the problems encountered by students when they read e-texts [9], [10], [11]. However, few studies have investigated ESL students from different disciplines in terms of reading preferences, gender differences, and which text type is better for comprehending the contents of the book. Therefore, the present paper explored whether international students' preferences (both males and females) have changed after the emergence of new tools and devices.

\subsection{Preferences for printed text}

A number of studies have reported preferring p-texts over e-texts when it comes for academic uses. [6] Conducted a study to investigate reading preferences among un- 
dergraduate students using a convenient survey. The findings revealed that students preferred reading p-texts (72\%) over e-texts $(7 \%)$. Students also reported that they found it easier to remember information read from p-texts (60.8\%) than e-texts. That is, if students were given choices regarding the type of text, they would choose paper texts $(71.7 \%)$. As a result, students tended to print out and read materials rather than read them online.

[8] Carried out a practical investigation to examine the preferences of 45 graduates and 41 undergraduates about using e-books for teaching and learning. Both groups showed positive attitudes towards the use of e-book readers and their e-book reading experiences. Surprisingly, graduate and undergraduate students preferred p-books over e-books and were still willing to use e-books and e-book readers for their studies.

[5] Surveyed 223 university students in the United States about their attitudes and preferences regarding reading from four types of books: loose-leaf, hardcover, paperback, and e-books. When the students were asked to choose their most preferred book, the students chose a printed textbook $(45.2 \%)$, followed by a hardback textbook (33.3\%) and the e-textbook (11.9\%). The students' main reasons for their preferences were ease of using printed textbooks, price, ownership, and health concerns.

Surprising results were found by [11] who surveyed 91 undergraduate students in the Department of Psychology. The study intended to determine e-book preferences and uses among students who had previous experience of using them. The results showed that even though the participants had satisfactory experiences in using ebooks and computers still preferred reading printed books rather than electronic ones. Students also reported that they would not purchase e-books, even though they were cheaper than the printed ones.

In an EFL context, [12] examined 495 college students' perceptions towards using e-books and related issues. The students were studying in different disciplines at various levels ranging from diploma to doctoral level. The results reported that students preferred printed books over e-books, at $65.98 \%$ and $17.60 \%$, respectively. In addition, the students used books for two main purposes: general information and academics.

\subsection{Preferences for electronic texts}

Conversely, [13] study was one of a few that supported a preference for e-texts. One of the five investigated framework points was the substituting of printed course materials with digital ones. Three ways were used to collect data: a special program software installed on an iPad, a questionnaire, and interviews with faculty and students. The study concluded that students and faculty preferred reading digital course materials. Furthermore, the faculty members recommended that students should use tablets for reading these materials. One of the reasons for this was the fact that the special software had the iAnnotate tool, which made reading e-books more helpful and enjoyable.

Along the same lines, [14] investigated the use of e-books, tablet computers, and reading habits among 100 undergraduate students in Turkey. The findings revealed that the majority of the students preferred using e-texts while studying with few health 
concerns because e-texts can be carried and read everywhere. The students' reading habits included reading through a tablet only, reading and taking notes either on a separate sheet, the pdf file, or the tablets.

\subsection{Pros and cons of both types of text}

Reading e-texts either online or on a tablet seems to be problematic. [9] carried out a study involving 20 undergraduate students by implementing a thinking-aloud strategy to investigate how the students used e-books versus printed books. The study revealed unique results. Even though students were considered highly computer literate, they did not know how to navigate and use e-texts effectively. Students reported that they got confused when they read e-texts because of the presentation. [15] also claims that the font size was an issue; some letters were too small or too big, while others were too hazy or too wide because of pixel limitations. [16] found that readers sometime felt fatigued when reading on computer screen. [9] mentions that "eye strain and fatigue from reading on a computer for a prolong time is perhaps the most common usability complaint among e-book users" (p. 519).

\section{Method}

\subsection{Participants}

The participants in the study were 60 non-native-English-speaking international students. 36 students were male and 24 were female. The students were at the beginning of their second and third semester at a midwestern university in the United States, majoring in 25 different disciplines. Their native languages were varied: Chinese (51.7\%), Korean (16.7\%), Arabic (15\%), Spanish (6\%), and other languages $(10 \%)$ including Indian languages, Portuguese, and African Languages. Table 1 shows the demographic characteristics of the participants.

Table 1. The demographic characteristics of the participants

\begin{tabular}{|c|c|c|c|c|}
\hline \multicolumn{2}{|l|}{ Demographic Information } & Frequency & $\%$ & Total Responses \\
\hline \multirow{2}{*}{ Gender } & Male & 36 & 60.0 & \multirow{2}{*}{60} \\
\hline & Female & 24 & 40.0 & \\
\hline \multirow{5}{*}{ Class } & Freshman & 2 & 3.3 & \multirow{5}{*}{60} \\
\hline & Sophomore & 20 & 33.3 & \\
\hline & Junior & 20 & 33.3 & \\
\hline & Senior & 1 & 1.7 & \\
\hline & Graduate & 17 & 28.3 & \\
\hline \multirow{4}{*}{$\begin{array}{l}\text { Self-reported Reading Comprehension } \\
\text { Ability }\end{array}$} & Moderate & 12 & 20.7 & \multirow{4}{*}{58} \\
\hline & Good & 28 & 48.3 & \\
\hline & Very Good & 16 & 27.6 & \\
\hline & Excellent & 2 & 3.4 & \\
\hline
\end{tabular}




\subsection{Instrument}

The data for this study were collected through a questionnaire designed to determine students' preferences in using e-texts compared to p-texts. The questionnaire consisted of two sections: the first section addressed reading course materials on electronic devices (i.e., tablets, laptops, cellphones) compared with p-texts. The section also included students' opinions and purposes regarding using e-devices for reading course materials as well as external materials. The second section elicited some demographic information such as gender, age, and language proficiency.

The questionnaire (see Appendix A) was partly adapted from [13] and then was developed by the author. The questionnaire was piloted with two Ph.D. TESL students to ensure there were no mistakes or ambiguities and to improve the word choices. Then the questionnaire was administered at the end of individual composition class periods with the help of instructors. All responses remained anonymous and confidential.

The reliability of the questionnaire was measured by Cronbach's Alpha. In this study, the Cronbach's Alpha was not available for the whole survey. Yet, question (8) about "How often do you use tablets for the following?" was the only measurable item. The main reason for this was that no other items shared a same Likert scale result. Each item had different rating scale designed to determine specific points related to the research questions. Item (8) was also important because it represented the fourth research question; What other uses of electronic devices (i.e., tablets) are there in nonacademic settings? Obviously, the results showed an acceptable internal consistency (reliability) for question (8) that consisted of nine subscale items $(a=.734)$.

\subsection{Data analysis}

Descriptive statistical procedures were applied by using SPSS software to analyze the obtained data. The aim was to examine the reading preferences of ESL students between e-texts and p-texts. The same procedures were applied to ascertain the extent to which the reading preferences varied by gender (males vs. females). Moreover, gender differences in terms of understanding e-texts compared to p-texts were analyzed using an independent $t$-test. Finally, the data were examined to determine the purposes of using electronic devices (i.e., tablets, laptops, cellphones) in the nonacademic environment. The results are presented in the next section.

\section{$4 \quad$ Results and Discussion}

The results obtained from the analysis in the study are shown and discussed in the following subsections. In general, students reported that they preferred reading course materials from p-text more than e-texts. The students also revealed that they used cellphones $(47 \%)$ and iPads (38\%) more frequently. 


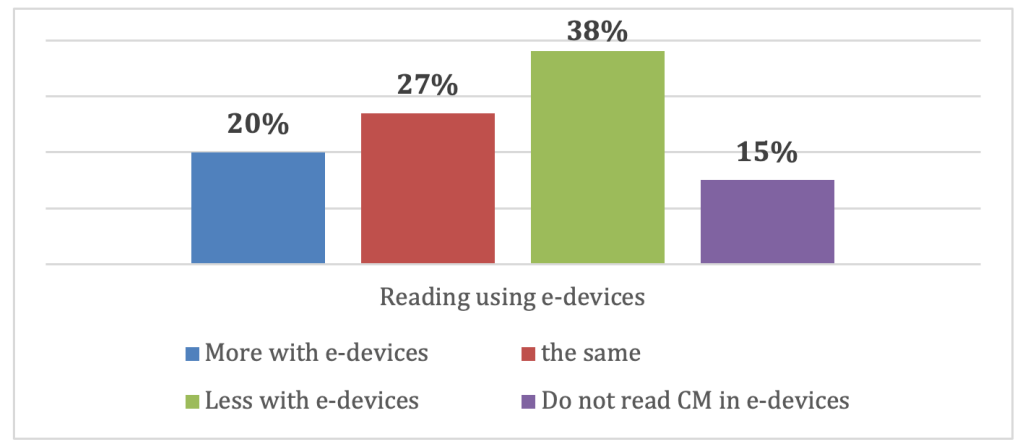

Fig. 1. Overall results of reading course materials on e-devices

\subsection{Students' preferences for using e-texts over p-texts}

Figure 1 shows the results of the first research question, which was designed to discover the students' preferences in using e-texts over p-texts. The results demonstrated that students who chose "more with a e-devices" most likely preferred reading their course materials through electronic devices (i.e., a tablet). In contrast, those who selected "less with e-devices" preferred using traditional books. Obviously, fewer students reported that they read course material on e-devices (i.e., e-books; 20\%) compared to traditional books $(38 \%)$. Other students reported that they did not read course materials on e-devices (15\%). Consequently, the amount of time spent on reading electronic texts was shorter than that spent for reading traditional texts. Almost half of the students spent much more time reading traditional books $(51 \%)$ than electronic books $(25 \%)$. The findings revealed that students preferred reading their course materials in a p-text format instead of an e-text. These findings support the previous studies mentioned in the literature review [6], [16], [7], [17].

On the other hand, the study contradicted the work of [13]. They found that students and faculty at the Naval War College preferred reading course materials on their electronic devices (i.e., tablets, laptops, and cellphones). One possible reason for this result could be related to a special application installed on the iPad of the participants. In the study, they implemented a new application called iAnnotate, which provided different, helpful, and enjoyable features. [18], as cited in [13], stated that:

"The iAnnotate application on the iPad provides annotation tools not inherent on the iPad for PDF files... It allows for annotations in the form of highlighting, underlining, free-form drawing, text notes, and bookmarking. Also, file structure is added through its PDF library with folders. In addition, multiple documents can be open simultaneously utilizing tabs to switch between them. Individual documents and the full library of PDFs can be searched." (p.46)

\subsection{Differences between males and females in terms of reading preferences}

Tables 2 and 3 present the results of the second research question about the differences between males and females regarding reading preferences. Both male and fe- 
male participants preferred reading traditional texts over the electronic ones. Statistically speaking, there was no difference between male and female participants in terms of e-text versus $\mathrm{p}$-text reading preferences $[t(60)=.523, \mathrm{p}<.050]$ and the amount of time spent on reading on e-devices $[t(60)=.975, \mathrm{p}<.050]$. The results also revealed that there was no statistical difference between male and female participants regarding reading course materials in e-texts compared to p-texts format. Even though the study agreed with a few of the previous studies, it contradicted [19] study. They discovered that female readers preferred using paper books $(73.2 \%)$ more than males $(51.3 \%)$. They also mentioned that females printed documents more often than males.

Table 2. Reading preferences by using e-devices based on gender

\begin{tabular}{|l|c|c|c|}
\hline & Male & Female & Total \\
\hline More with e-devices & 9 & 3 & 12 \\
\hline The same & 10 & 6 & 16 \\
\hline Less with e-devices & 10 & 13 & 23 \\
\hline Do not read course materials in Tablet & 7 & 2 & 9 \\
\hline Total & 36 & 24 & 60 \\
\hline Mean & 2.42 & 2.58 & 5 \\
\hline
\end{tabular}

Table 3. Period of reading on e-devices based on gender

\begin{tabular}{|l|c|c|c|}
\hline & Male & Female & Total \\
\hline Longer with e-devices & 8 & 7 & 15 \\
\hline The same & 10 & 4 & 14 \\
\hline Shorter with e-devices & 17 & 13 & 30 \\
\hline Total & 35 & 24 & 59 \\
\hline Mean & 2.26 & 2.25 & 4.51 \\
\hline
\end{tabular}

\subsection{Difference between males and females in terms of comprehending with e- text or t-text}

Figures 2 and 3 presents the results obtained to answer the third research question about difference between males and females in terms of comprehending with e-text over t-text. The most important reasons behind preferring traditional texts over electronic texts was that students comprehended more when they read t-texts than e-texts. The results showed that $55 \%$ of students understood information read from p-text, while approximately $38 \%$ reported that they understood less when they read from $\mathrm{t}$ text. On the other hand, few students $(10 \%)$ reported that they understood when they read from e-text, while (52\%) stated that they understood less when they read from etext. Statistically, the t-test was applied to find out the differences between males and females. The results revealed that there was a statistical difference between male $(\mathrm{m}=1.67)$ and female $(\mathrm{m}=1.29)$ participants in terms of comprehension when reading t-text $[t(60)=.020, \mathrm{p}>.050]$. In other words, females understood more than males when they read documents in a t-text format. The previous studies investigated reading comprehension in relation to reading strategies; [20] found that there was no significant difference between controlled and treatment groups in terms of reading comprehension. 


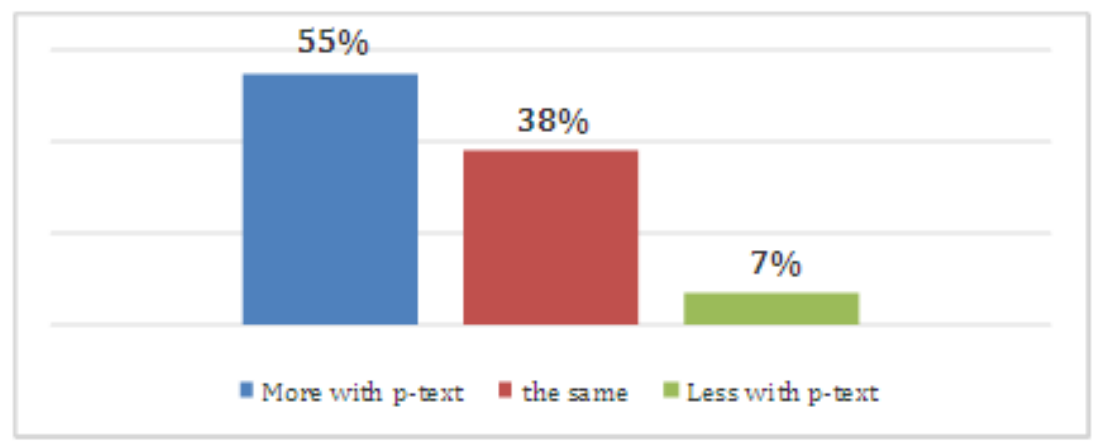

Fig. 2. Overall Results of understanding content when reading from p-text

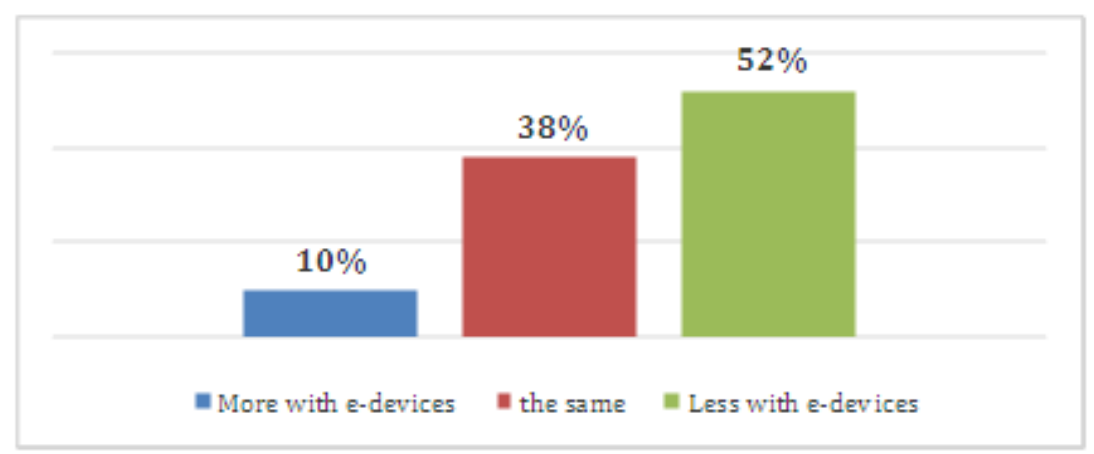

Fig. 3. Overall results of understanding content when reading on e-devices

\subsection{Different uses of uses of electronic devices}

Finally, Table 4 presents the answers for the last research question. Students preferred using electronic devices (i.e., tablets) to browse the Internet $(\mathrm{m}=3.43)$, to listen to or watch media $(m=3.41)$, to read emails $(m=3.40)$, and to write emails $(m=3.02)$. As for reading course materials, the mean was 2.54 out of 4.00 . With regards to personal uses of electronic devices compared to academic uses, approximately $56 \%$ of the students frequently used tablets for personal uses, compared with $13 \%$ for academic uses.

The results of the fourth research question revealed the frequent uses of electronic devices (i.e., tablets) in nonacademic settings. It was clear that students preferred using e-devices for personal reasons compared to academic ones. Such personal uses were web browsing, listening to or watching media, and reading and writing emails. These results clearly described what was mentioned earlier about reading preferences. Students preferred using p-text for reading course materials, whereas they preferred using tablets for personal reasons. Note-taking was the feature least used by students. However, [21] suggested that matrix style note-taking successfully improved college students' online learning. 
Table 4. The overall results for the purposes of using e-devices

\begin{tabular}{|c|c|c|c|c|c|c|c|c|}
\hline $\begin{array}{c}\text { Web } \\
\text { Browsing }\end{array}$ & Media & $\begin{array}{c}\text { Reading } \\
\text { Emails }\end{array}$ & $\begin{array}{c}\text { Writing } \\
\text { Email }\end{array}$ & $\begin{array}{c}\text { News } \\
\text { Reading }\end{array}$ & Gaming & $\begin{array}{c}\text { Reading } \\
\text { Courses } \\
\text { Materials }\end{array}$ & $\begin{array}{c}\text { Answering } \\
\text { Assignments }\end{array}$ & $\begin{array}{c}\text { Note Tak- } \\
\text { ing }\end{array}$ \\
\hline 3.43 & 3.41 & 3.40 & 3.02 & 2.90 & 2.67 & 2.54 & 2.37 & 1.93 \\
\hline
\end{tabular}

\section{Conclusion}

The main purpose of the study was to investigate the reading preferences of ESL students in terms of e-text compared to p-text. In addition, the study investigated the influence of reading e-text or p-text on comprehending the contents. The purposes of using electronic devices among students were also explored. The findings indicated that students preferred using p-text over e-text. Moreover, the results indicated a significant difference between male and female participants in terms of understanding content being read in a printed format. Lastly, students preferred using electronic devices for personal uses rather than academic.

This study suggested several pedagogical implications. First, since few studies have revealed strong uses or preferences of e-text, it is likely the participants in these studies were given special tools. Therefore, application developers have to invent more helpful applications for tablets as well as computers. Second, students need to familiarize themselves with the technological revolution of electronic texts. Students also have to take advantage of the reasonable prices of e-books available in online stores. Lastly, e-book developers need to take a significant step forward in designing new e-books platforms and formats to convince readers to use e-books rather than printed books.

The present study had some limitations. It investigated the reading preferences of course materials among ESL students and the frequent uses of electronic devices in different settings. Other studies are worthwhile to investigate in details the reasons behind this preference. Since the self-reported English proficiency level was not equal between the highly proficient (16) and moderately proficient (43), it was not possible to make a comparison between both groups.

\section{Acknowledgement}

Special thanks go to the instructors in the English Department at the university for their help in the current study.

\section{$7 \quad$ References}

[1] B. A. Smith, A quantitative analysis of the impact of e-book format on student acceptance, usage and satisfaction (Doctoral dissertation). ProQuest Dissertations \& Theses database (UMI No. 3329848), p. 12, 2008. 
[2] M. T. McCrudden, J. Magliano, and G. Schraw, The effects of diagrams on online reading processes and memory. Discourse Processes, vol. 48, no. 2, p. 70, 2011. https://doi.org/10.1080/01638531003694561

[3] K. Martin and A. Quan-Haase, Are e-books replacing print books? Tradition, serendipity, and opportunity in the adoption and use of e-books for historical research and teaching. Journal of the American Society for Information Science and Technology, vol. 64, no. 5, p. 1016, 2013. https://doi.org/10.1002/asi.22801

[4] N. Tosun, A study on reading printed books or e-books: Reasons for student-teachers preferences. Turkish Online Journal of Educational Technology-TOJET, vol. 13, no. 1, pp. 2128, 2014.

[5] D. R. Edmondson and C. Ward, Students' Attitudes towards Textbook Types: Are Students Really Ready for E-Textbooks? Atlantic Marketing Journal, vol. 5, no. 3, pp. 1-13, 2017.

[6] A. B. Hamer and J. McGrath, On-screen vs. on-page reading strategies. Session conducted at the meeting of College Reading and Learning Association, Salt Lake City, UT, Nov. 2010 .

[7] A. Noorhidawati and F. Gibb, How students use e-books - reading or referring? Malaysian Journal of Library \& Information Science, vol. 13, no. 2, pp. 1-14, 2008.

[8] S. Shin, E-book usability in educational technology classes: Teachers and teacher candidates' perception toward e-book for teaching and learning. International Journal of Distance Education Technologies (IJDET), vol. 12, no. 3, pp. 62-74, 2014. https://doi.org/10.4018/ijdet.2014070105

[9] S. A. Berg, K. Hoffman, and D. Dawson, Not on the same page: Undergraduates' information retrieval in electronic and print books. The Journal of Academic Librarianship, vol. 36, no. 6, pp. 518-525, 2010. https://doi.org/10.1016/j.acalib.2010.08.008

[10] L. Le Bigot and J-F. Rouet, The impact of presentation format, task assignment, and prior knowledge on students' comprehension of multiple online documents. Journal of Literacy Research, vol. 39, no. 4, pp. 445-470, 2007. https://doi.org/10. $\underline{1080 / 10862960701675317}$

[11] W. D. Woody, D. Daniel, and C. A. Baker, (). E-books or textbooks: Students prefer textbooks. Computers \& Education, vol. 55, no. 3, pp. 945-948, 2010. https://doi.org /10.1016/j.compedu.2010.04.005

[12] K. Al Saadi, M. Lane-Kelso, A. Al Hafeedh, Z. Al Sheithani, and M. Al Wishahi, Are We Ready for E-Books? Omani University Students' Uses and Perceptions of E-Books. Turkish Online Journal of Educational Technology-TOJET, vol. 16, no. 2, pp. 11-25, 2017.

[13] M. H. Bush and A. H. Cameron, Digital course materials: A case study of the apple iPad in the academic environment. Pepperdine University, 2011.

[14] Ö. Koçak, Ö. Yıldırım, E. Kurşun, and G. Yıldırım, Investigating the Status of Tablet Computers and E-Books Use of Open Education Faculty Students: A Case Study. International Journal of Distance Education Technologies (IJDET), vol. 14, no. 2, pp. 49-63, 2016. https://doi.org/10.4018/IJDET.2016040104

[15] K. Larson, The technology of text. IEEE Spectrum, vol. 44, no. 5, pp. 26-31, 2007. https://doi.org/10.1109/MSPEC.2007.352529

[16] Z. Liu, Reading behavior in the digital environment: Changes in reading behavior over the last ten years. Journal of Documentation, vol. 61, no. 6, pp. 700-713, 2005. https://doi.org/10.1108/00220410510632040

[17] C. Spencer, Research on learners' preferences for reading from a printed text or from a computer screen. Journal of Distance Education, vol. 21, no. 1, pp. 33-50, 2006.

[18] Aji. iAnnotate. Retrieved from http://www.ajidev.com/iannotate/index.html, p. 46, 2010. 
[19] Z. Liu and X. Huang, Gender differences in the online reading environment. Journal of Documentation, vol. 64, no. 4, pp. 616-626, 2008. https://doi.org/ $\underline{10.1108 / 00220410810884101}$

[20] H. Dundar, and M. Akcayir, Tablet vs. paper: The effect on learners' reading performance. International Electronic Journal of Elementary Education, vol. 4, no. 3, pp. 441-450, 2012.

[21] D. F. Kauffman, R. Zhao, and Y-S. Yang, Effects of online note taking formats and selfmonitoring prompts on learning from online text: Using technology to enhance selfregulated learning. Contemporary Educational Psychology, vol. 4, pp. 1-10, 2011. https://doi.org/10.1016/j.cedpsych.2011.04.001

\section{Author}

Basim Alamri is an Assistant Professor in the English Language Institute at King Abdulaziz University, Saudi Arabia. His research interests revolve around topics related to L2 academic writing, including genre studies and corpus linguistics, and technology in the classroom.

Article submitted 1 September 2018. Resubmitted 29 November 2018. Final acceptance 13 December 2018. Final version published as submitted by the authors. 